\title{
Influence of climate on tree mortality in taiwania (Taiwania cryptomerioides) stands in Taiwan
}

\author{
Chih-Ming Chiu', Ching-Te Chien ${ }^{1}$, Gord Nigh ${ }^{2 *}$ and Chih-Hsin Chung ${ }^{1}$
}

\begin{abstract}
Background: Taiwania (Taiwania cryptomerioides Hayata) is a relict tree species found mainly in Taiwan, with smaller populations in China, Vietnam, and Myanmar. Taiwania is considered to be vulnerable to extinction. The objective of this research was to develop a model to predict the mortality of taiwania from climate and other mensurational variables.
\end{abstract}

Methods: The mensuration, mortality, and climate data came from permanent sample plots established as thinning experiments and a nearby climate station. The data were analysed using logistic regression with individual tree mortality as the response variable.

Results: The important predictor variables of mortality were social status [defined as diameter at breast height (dbh) divided by average dbh] and annual precipitation in the year of death. The probability of mortality increased as social status decreased and as annual precipitation increased. The positive correlation between mortality and precipitation is likely a consequence of typhoons since precipitation and mortality caused by wind throw both result from typhoons.

Conclusions: Climate change could increase the number and severity of typhoons occurring in Taiwan. This may increase the mortality rate of taiwania, which would detrimentally affect the viability of taiwania populations.

Keywords: Climate change, Logistic regression, Precipitation, Self-thinning, Typhoon

\section{Background}

The climate of Taiwan ranges from subtropical in the northern and central regions to tropical in the south and temperate in the mountainous regions. East Asian winter monsoons bring precipitation to the east and north of Taiwan while the south has little rain in the winter. Conversely, East Asian summer monsoons bring typhoons that can be damaging to south-western Taiwan (Executive Yuan 2014). For example, typhoon Morakot deposited $2965 \mathrm{~mm}$ of rain over a 4-day period in August 2009, with a peak 24-h rainfall of $1623.5 \mathrm{~mm}$ (Wu 2013). Taiwan experiences many typhoons each year and has one of the highest frequencies of tropical typhoons globally (Lin et al. 2017). Climate strongly affects forest types in Taiwan. Broadleaf forests are generally found at lower elevations but

\footnotetext{
* Correspondence: gordon.nigh@gov.bc.ca

${ }^{2}$ Ministry of Forests, Lands and Natural Resource Operations, P.O. Box 9512,

Stn. Prov. Govt., Victoria, BC V8W 9C2, Canada

Full list of author information is available at the end of the article
}

graduate into coniferous forests at higher elevations. Climate change poses a considerable threat to these ecosystems due to the influence of temperature and moisture gradients on forests (Li et al. 2013).

Fourteen tree species are currently of conservation concern in Taiwan. One of these is taiwania (Taiwania cryptomerioides Hayata), which is a species considered vulnerable to extinction (Thomas and Farjon 2016; World Wildlife Fund 2017). This species has been over-harvested because wood from taiwania is valuable for use in furniture making. Logging in national natural forests in Taiwan was prohibited in 1992 to protect forests from overexploitation and clearcutting, particularly on mountain slopes, and to provide wildlife habitat (Shang 2013). Due to these conservation measures, the population of taiwania is currently stable although vulnerable (Thomas and Farjon 2016). Commercial logging is now done in plantations, and the annual harvest of all tree species is typically less than $50,000 \mathrm{~m}^{3}$ per year (Shang 2013). 
Taiwania is a tertiary relict species. Its range used to extend from North America to Russia, Norway, and Germany (He et al. 2015). Now, taiwania is mainly found in Taiwan, with small fragmented stands in China ( $\approx 55,275$ trees), Vietnam (<100 trees), and Myanmar (accurate information on the size of Myanmar populations are not available) (He et al. 2015; Thomas and Farjon 2016). Taiwania is very long-lived ( $>1600$ years) and can grow to be a large tree, up to $60 \mathrm{~m}$ tall with a diameter of $2-3 \mathrm{~m}$. It is found at higher elevations from 1500 to $2600 \mathrm{~m}$ (Huang et al. 1994; Wang and Chien 2016) and usually grows in mixed conifer stands but also sometimes grows with angiosperms (Thomas and Farjon 2016). There are few ecological studies on taiwania (He et al. 2015). Natural taiwania stands are found in humid, foggy mountainous areas, but managed stands grow in climates ranging from wet to dry (He et al. 2015). Taiwania is shade-intolerant and regenerates in canopy gaps created mostly by uprooted trees, standing dead trees, or irregular topographies such as cliffs and steep slopes. Seedlings are rare in closed canopies. Taiwania seeds cannot germinate under leaf litter on stable sites, but the seeds are small and are easily dispersed by wind. Germination rates are low at < 35\% (Wang and Chien 2016), and germination occurs on disturbed sites with exposed mineral soil (He et al. 2015). Taiwania can achieve height growth rates of 1 mper year and diameter growth rates of $1 \mathrm{~cm}$ per year and can produce $600 \mathrm{~m}^{3}$ per hectare by age 40 on good sites (Kuo, 1995).

The direct effects of increased carbon dioxide concentrations and climate change on tree growth are complex and inconsistent (Camarero et al. 2015). An increased concentration of carbon dioxide typically has a fertiliser effect (Nowak et al. 2004; Ainsworth and Long 2005; Bugmann and Bigler 2011). The effects of climate change on tree growth are dependent on both the direction and magnitude of the change in temperature and precipitation. Trees from colder environments may show an increased growth response to warmer temperatures whereas tropical species may show a reduction in growth with either an increase or decrease in temperature (Wang et al. 2010; Way and Oren 2010; Pedlar and McKenney 2017). Additionally, a lack of moisture availability can reduce tree growth (Chen et al. 2017), but some species are adapted to drought conditions and are less affected by moisture stress than others (Xu et al. 2015). There is growing evidence that variability and extremes in precipitation are more important factors in ecosystem processes than annual amounts of precipitation (Zeppel et al. 2014, Xu et al. 2015). Indirect effects of climate change on tree growth and survival, such as increased insect attacks and fires, also pose considerable threats (Taylor et al. 2006; Ryan 2010).
Tree mortality is difficult to predict, partly because there can be many factors that interact to cause enough stress for a tree to die (Franklin et al. 1987). A changing climate can result in stress on trees that are adapted to a certain climate. Warmer temperatures that increase respiration rates without a commensurate increase in photosynthesis can result in tree stress (Waring 1987) as can extended drought conditions, particularly for species not well-adapted to dry climates (Waring 1987, Bigler et al. 2007). These stressors, either alone or in combination with other stressors such as insect attack, disease, or competition, can result in mortality.

The vulnerability status of taiwania makes it all the more important to understand the potential effects of climate change on this species. Increasing mortality rates may be indicative of a forest under stress (van Mantgem et al. 2009). Consequently, this research seeks to develop a model to predict individual tree mortality from climate variables, as well as stand-level and tree-level variables. The inclusion of climate variables in the model will identify key climate drivers that affect mortality of taiwania in Taiwan and quantify those effects. This will provide insights into the effects of climate change on the continuance of this species.

\section{Methods}

\section{Study sites}

The mortality data for this study come from two thinning experiments, one in Compartment 3 and the other in Compartment 12 of the Liu-kuei Experimental Forest (longitude $120^{\circ} 42^{\prime} 51^{\prime \prime}$, latitude $23^{\circ} 00^{\prime} 14^{\prime \prime}$ ) of the Taiwan Forestry Research Institute (Kaohsiung City), which is in a mountainous area of south-central Taiwan. The sites are at an elevation of 1500-1600 m with slopes of about $15-30^{\circ}$. The mean annual rainfall is $2200 \mathrm{~mm}$, the average annual temperature is $18.7{ }^{\circ} \mathrm{C}$, and the average relative humidity is $85 \%$. Compartment 3 has a south-western aspect, and Compartment 12 has a southeastern aspect.

The experiment in Compartment 3 was planted in 1972 at a target of 2500 stems per hectare (sph). It was thinned in 1986 (at age 14) and again in 2003 (at age 31). The thinning treatments consisted of an unthinned control and three levels of thinning. Each treatment was conducted on 4 plots that were 0.04 ha in size. The thinning at age 14 left 1300, 1125, 975, and 1980 (the control plots) sph, and the thinning at age 31 left 800 , 600, 425, and 1730 (control) sph. The plots were measured at irregular intervals from 1981 to 2011.

The experiment in Compartment 12 was planted in 1979 at a target of 1750 sph and was thinned in 1990 at age 11. There were two levels of thinning (heavy and medium) as well as an unthinned control. Each treatment was conducted on 12 plots that were 0.04 ha in 
size. The target basal areas after the thinning treatments were 27.5 (heavy), 32.5 (medium), and 42.0 (control) $\mathrm{m}^{2}$ ha $^{-1}$. This left an average of 930 (range 700-1400), 1137 (range 857-1725), and 1806 (range 1375-2500) sph for the heavy, medium, and control treatments, respectively. The plots were measured at irregular intervals from 1990 to 2011.

\section{Field measurements}

Measurements for both installations were taken in November and December, after the growing season ended. Diameter at breast height (dbh) was recorded at each measurement. Mensuration data for the plots in Compartments 3 and 12 are provided in Additional files 1 \& 2, respectively. Trees that died were identified by having a dbh at one measurement but not at the subsequent measurement. Trees that were removed by thinning were identified in the dataset so that they could be differentiated from the trees that died. The variable STATUS was created to give a continuous measure of the social status of each tree in the plot. Social status is the relative position of a tree in the height distribution (United Nations Economic Commission for Europe International Co-operative Programme Coordinating Centre 2016). Lacking consistent height measurements, STATUS was calculated by dividing the dbh of a tree by the average dbh of all trees in the plot. The variable DENSITY (sph) was calculated as the number of trees in a plot divided by the plot size in hectares.

\section{Climate data}

The climate data came from a climate station established less than $2 \mathrm{~km}$ from the two installations. Climate data were available for most years from 1980 to 2013 (see Additional file 3), except for 1996, 1997, and 1998, which were missing and unrecoverable. The climate data consisted of daily minimum, maximum, and average temperatures $\left({ }^{\circ} \mathrm{C}\right)$ as well as daily precipitation $(\mathrm{mm})$ from which a number of climate variables could be calculated. However, since these climate variables would be derived from the same data, using all of them as predictor variables in a model would lead to serious multicollinearity. Therefore, only the variables mean annual temperature (MAT, ${ }^{\circ} \mathrm{C}$ ), annual precipitation (AP, $\mathrm{mm}$ ), mean growing season temperature $\left(\mathrm{MGST},{ }^{\circ} \mathrm{C}\right)$, growing season precipitation (GSP, $\mathrm{mm}$ ), and growing degree days $>5{ }^{\circ} \mathrm{C}$ (DD5) were considered, and these were chosen because they are related to tree growth. The growing season is March to October, inclusive, based on the information in Chang et al. (2011) and Chung and Kuo (2005).

\section{Statistical analyses}

Only measurements that were taken on consecutive years were analysed so that the time of tree mortality could be isolated to a particular year, and consequently, the annual climate information could be correctly matched to the year of mortality. Logistic regression (Hosmer and Lemeshow 2000) was used to identify which climate attributes affected the mortality rates of taiwania. This approach was used as it is well-suited for handling data where it is only known that the event being studied occurred between two times and for handling covariates that change over time, such as the climate variables studied here (Allison 2010). The complementary log-log model for continuous-time processes was used because the events (mortality) occurred in continuous time but were grouped into intervals (Allison 2010). A mixed effects model was fitted to the data to account for potential differences between the two sites. The link function, which is the model, is

$$
\log \left[-\log \left(1-P_{i j t}\right)\right]=\alpha+u_{i}+\beta_{1} \times x_{i j t 1}+\ldots+\beta_{k} \times x_{i j t k}
$$

where $P_{i j t}$ is the conditional probability that an event (that is, tree mortality) occurs to individual $j$ at site $i$ ( $i=$ Compartment 3 or 12) during time period $t ; x_{i j t 1}$ to $x_{i j t k}$ are $1-k$ time-dependent covariates that affect tree mortality; $\alpha, \beta_{1}, \ldots, \beta_{k}$ are parameters to be estimated; and $u_{i}$ is a random effect that allows the intercept to vary across the two sites. The data analysis was conducted with procedure NLMIXED in SAS (SAS Institute Inc. 2011).

The variables tested for significance in the model were chosen for their potential to be related to mortality. The covariates of interest were DBH, STATUS, DENSITY, MAT, AP, MGST, GSP, and DD5. The climate variables were of most interest, but other variables, such as Bt (basal area of all neighbours) and $\mathrm{Bl}$ (basal area of taller neighbours) (Coomes and Allen 2007) were included in the model initially to capture unexplained variation and give some insights into the processes leading to tree death, particularly self-thinning. Climate variables for the year after the trees were measured, and the year that the trees were measured were denoted by a 0 and -1 , respectively, in parentheses following the variable name. The climate in the year following the measurements was important because the measurements were done at the end of the year, making the following year of central importance. The data from the year that the trees were measured was analysed to determine if there was a lag effect between climate and tree mortality, as has been reported elsewhere (e.g. Bigler et al. 2007; Suresh et al. 2010). To reduce multicollinearity in the model due to correlation between the climate variables, only one temperature-related variable, one precipitation-related variable, and their lagged counterparts were admitted in the model. The variables that were not significantly different from 0 at a 0.05 significance level were removed from the model. The best model was identified as the model with the smallest Akaike information criterion 
(AIC; Burnham and Anderson 2002). Variable importance was assessed by re-fitting the model after removing each variable one-at-a-time and calculating the change in the AIC from the full model to the reduced model. This is similar to a method that uses $R^{2}$ instead of AIC to assess the importance of individual variables (Grömping 2007).

The fitted model was examined using the goodness-offit test by Hosmer and Lemeshow (2000). A further check on the goodness-of-fit was done by plotting the expected and actual number of trees that died against the predictor variables in the final fitted model. To make these graphs, individual tree data were grouped into deciles based on the value of each predictor variable. Then, within each decile grouping, the predicted and actual number of trees that died were summed and plotted against the average of the predictor variable within each decile.

\section{Results}

The mortality rates in the study sites were not high, ranging from $0 \%$ in 1994 and 1995 to $1.8 \%$ in 2004 (Fig. 1). The significant predictor variables for tree mortality were STATUS and $\mathrm{AP}(0)$, and these are summarised in Table 1. Replacing variable $\mathrm{AP}(0)$ with $\mathrm{GSP}(0)$ resulted in a similar model because annual and growing season precipitation were highly correlated $(r>0.975)$ due to very little precipitation falling outside of the growing season. However, fitting the model with $\mathrm{AP}(0)$ instead of $\mathrm{GSP}(0)$ resulted in a model with a slightly smaller AIC. Self-thinning theory suggests that DENSITY would be an important predictor variable (Westoby 1984; Yoda et al. 1963); however, the

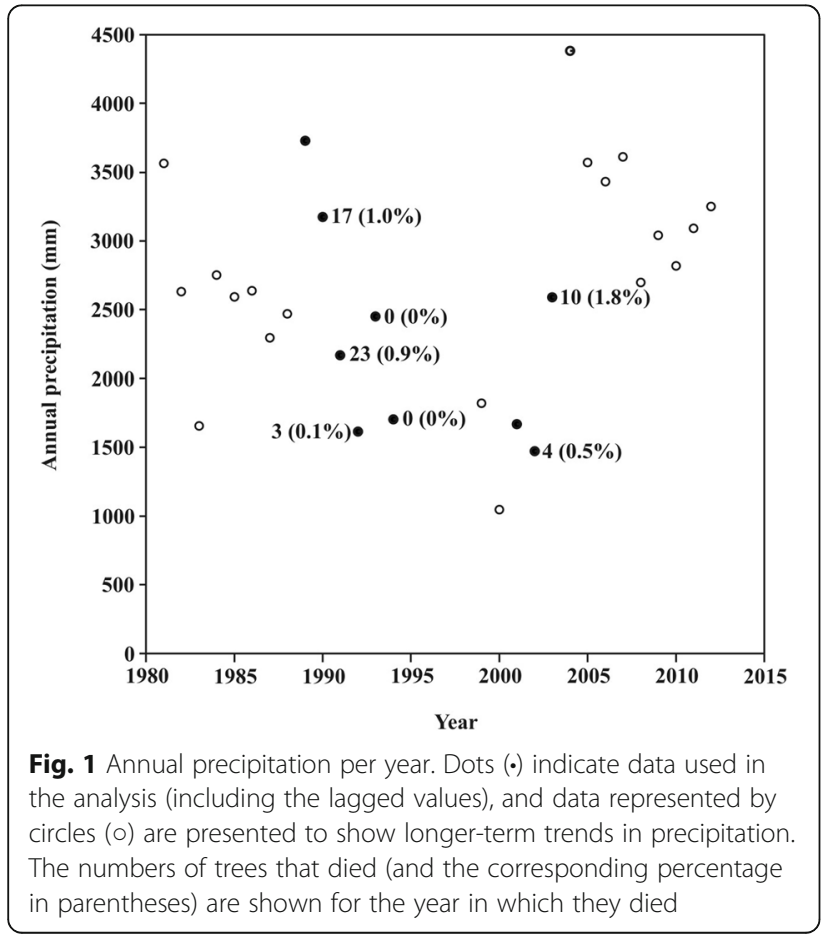

Table 1 Summary information for the significant predictor variables (STATUS and AP(0)) in the final fitted model

\begin{tabular}{llll}
\hline Variable & Mean & Minimum & Maximum \\
\hline STATUS & 1.00 & 0.11 & 1.76 \\
AP(0) $(\mathrm{mm})$ & 2168 & 1473 & 3175 \\
DBH (cm) & 21.0 & 2.0 & 49.7 \\
DENSITY (sph) & 1247 & 425 & 2500 \\
\hline
\end{tabular}

Variables DBH and DENSITY are also included in this table to give an indication of the stand structure

variable STATUS alone accounted for self-thinning mortality. The final fitted model (Table 2 ) for the probability of a tree dying $(P)$ was

$$
P=1-e^{-e^{-4.89+u-4.74 \times \operatorname{STATUS}+0.00170 \times \mathrm{AP}(0)}}
$$

This model indicated that the probability of a tree dying increased as STATUS decreased and as $\mathrm{AP}(0)$ increased. The variance of the random effect $u$ was 1.25 , and the values of $u$ were 1.12 and -1.08 for Compartments 3 and 12, respectively.

The AICs for the final fitted model and the null model were 607 and 724, respectively, indicating that there was a substantial support for the fitted model (Burnham and Anderson 2002). The change in AIC ( $\triangle$ AIC; Table 2 ) of the fitted model after removing the variables one-at-a-time indicates that STATUS was more important than $\mathrm{AP}(0)$ in predicting mortality and that there was no support for removing either variable from the model (Burnham and Anderson 2002). Variable Bt was not significant. Bl was significant but not with variable STATUS in the model. Based on the AIC, STATUS was a better predictor of mortality than $\mathrm{Bl}$, so STATUS was used as a predictor variable of self-thinning. The Hosmer and Lemeshow goodness-of-fit statistic was $1.60(p=0.99)$, indicating that the hypothesis that the complementary log-log model with variables STATUS and $\mathrm{AP}(0)$ was the correct model cannot be rejected. The goodness-of-fit of the model can be seen in graphs of the actual and predicted number of trees that died (Fig. 2).

Table 2 Parameter estimates for the variables in the final fitted model, their standard errors, and $\triangle \mathrm{AIC} . \triangle \mathrm{AIC}$ is the increase in AIC when the variable is removed from the model and is an indicator of the importance of the variable

\begin{tabular}{llll}
\hline Variable & Estimate & Standard error & $\triangle$ AIC \\
\hline Intercept & -4.89 & 1.18 & \\
STATUS & -4.74 & 0.577 & 60 \\
AP(0) & 0.00170 & 0.000291 & 38 \\
\hline
\end{tabular}




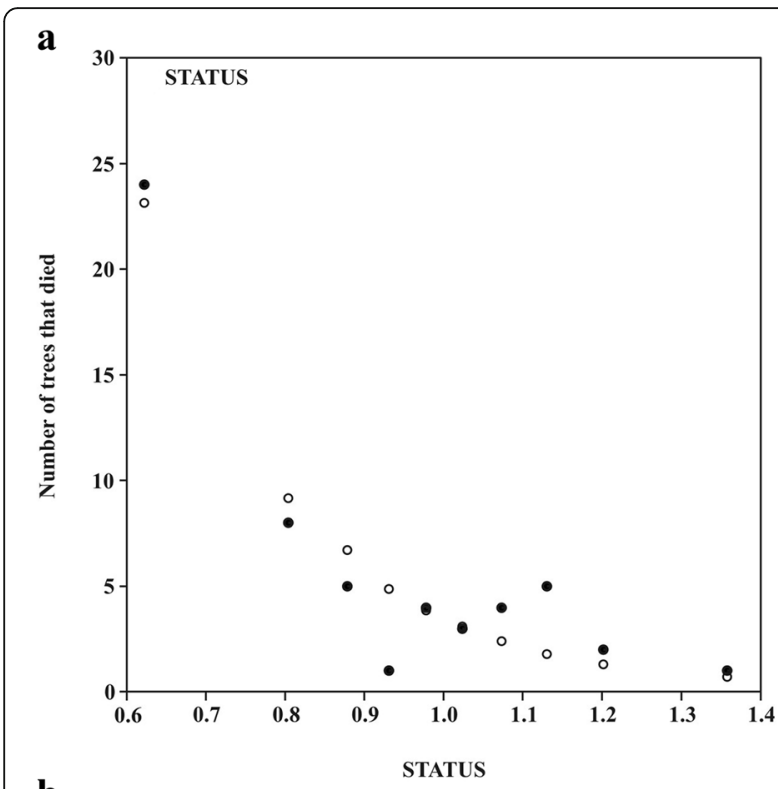

b

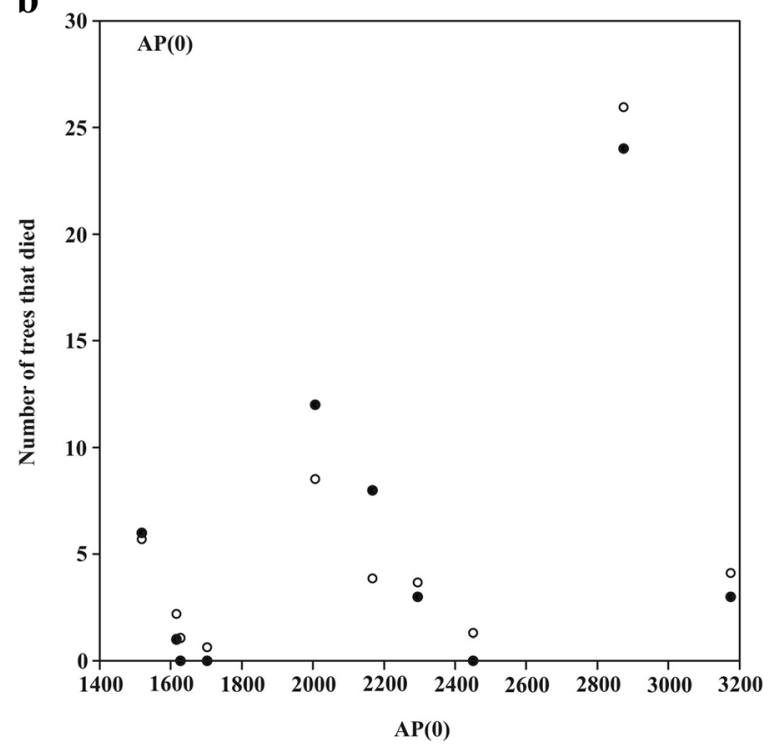

Fig. 2 Predicted circle (o) and actual dot (•) number of trees that died by decile of the variables STATUS (a) and AP(0) (b)

\section{Discussion}

\section{Drivers of mortality}

The importance of the variable STATUS in the model indicates that self-thinning is occurring. Seventy-four per cent of the trees that died had a smaller than average dbh (Fig. 2a). Of the trees that died, all those that had a value less than 0.8 for STATUS came from the control plots where no thinning treatments had occurred, making it likely that some of these trees succumbed to selfthinning. The lack of dead trees with STATUS $<1.0$ in the treated plots may be an artefact of the removal of small trees by the thinning treatment. Mortality due to self-thinning will not be discussed further since this research is focused on the relationship between mortality and climate.

Annual precipitation in the year of death $[\mathrm{AP}(0)]$ is a significant predictor of taiwania mortality in the study plots. The positive coefficient for variable $\mathrm{AP}(0)$ signifies that mortality increases as precipitation increases. This, along with the annual precipitation data (Fig. 1), eliminates drought as a cause of mortality. Excess soil moisture can reduce the amount of oxygen in the soil and can lead to tree death (Kozlowski 1984). This is unlikely to be the cause of tree mortality in these stands because the high amounts of precipitation are usually the result of a few days rain from typhoons and most of this moisture becomes runoff on these steep slopes. Some stress on the trees may have resulted from nutrient leaching. High levels of precipitation due to typhoons at a research site in northern Taiwan resulted in the leaching of nutrients from the soil (Lin et al. 2011), but the loss of nutrients due to leaching only lasted for a short time and slow decomposition rates of leaf litter at the site allows trees to take up most of the mineralised nutrients before they are leached away. The most likely explanation for the increase in mortality with an increase in growing-season precipitation is that storms (especially typhoons) lead to high precipitation and also high winds that result in wind throw. The year in which the second highest mortality occurred was 1990, which was also the year with the highest amount of precipitation in which mortality was analysed (Fig. 1). The cause of tree mortality was not recorded so it is not possible to test the hypothesis that soil moisture or wind throw cause mortality rather than precipitation, but future observations on these and other plots could verify or refute these propositions.

At the Fushan Experimental Forest in northern Taiwan, only $1.4 \%$ of the trees experienced stem breakage or uprooting by typhoon Herb (a category-3 typhoon) that passed directly over the forest (Lee et al. 2008). Damage from the same typhoon was more extensive at the Lienhuachi Experimental Forest in central Taiwan. Lee et al. (2008) attributed this to the lower frequency of typhoons at the Lienhuachi forest and concluded that native forests that experience more typhoons are more resistant to typhoons. Damage to trees in other parts of the world that experience fewer typhoons tends to be much greater than in Taiwan and trees could not persist if blowdown was as severe in Taiwan as in other regions of the world (Lee et al. 2008, Lin et al. 2011).

The high frequency of typhoons in Taiwan leads not only to increased resistance but also to increased resiliency to typhoons (Chi et al. 2015; Lin et al. 2011). Tall trees are removed by typhoons, leaving stands that are shorter in stature and hence more resistant to typhoons. The large amount of defoliation caused by the high 
winds from typhoons also generates resistance to breakage and uprooting. Resiliency is achieved through gaps in the canopy formed by wind throw. This creates microhabitats with elevated temperatures and light, which are suitable for regeneration of shade-intolerant species such as taiwania. The rapid recovery of foliage loss after typhoons also aids resilience. The ecosystems in Taiwan are stable due to the resistance and resilience of the forests to typhoons. An increase in the frequency or severity of typhoons could destabilise the ecosystems of Taiwan (Lin et al. 2017).

\section{Climate change and mortality}

Climate change in Taiwan is occurring. Continuous monitoring of temperature and precipitation in Taiwan began in 1896 at six climate stations, resulting in a good record of climate for over a century at these stations (Hsu et al. 2011). Of these six climate stations, the one closest to the study plots is located at Tainan, about $50 \mathrm{~km}$ west of the study plots. Over the last 100 years, the temperature at Tainan has increased by about $0.2{ }^{\circ} \mathrm{C}$ per decade, but has increased by $0.3{ }^{\circ} \mathrm{C}$ per decade in the last 30 years. Over the same periods, precipitation has decreased by 3 and $4.9 \%$ per decade, respectively. The models generated in the current study predict that there should be a decline in mortality as precipitation decreases. However, the number of moderate and intense typhoons affecting Taiwan has increased over the last 30 years, as has the number of days with torrential rain, which could lead to an increase in mortality.

Projections of annual precipitation at the end of the twenty-first century in southern Taiwan based on the A1B scenario are highly variable and range from a decrease of $31 \%$ to an increase of 55\% (Hsu et al. 2011). The A1 scenario assumes rapid economic growth, a population that peaks in mid-century and then declines, and the rapid development of new efficient technology. The B group within the A1 scenario assumes a balanced use of fossil and non-fossil energy sources. The frequency of severe typhoons with intense precipitation has increased in Taiwan recently, but there is significant inter- and intraannual variation so projections for the future are unclear (Hsu et al. 2011). There is a trend of more precipitation associated with typhoons and even less precipitation in the dry winter season. Furthermore, there is evidence that the warmer temperatures expected as a result of climate change will increase the intensity of typhoons in the northwestern Pacific Ocean (Mei et al. 2015).

The results of this research combined with projected future climate change suggest that mortality in young stands of taiwania may increase in the future. If the correlation between precipitation and mortality is due to typhoons, then mortality will increase if the frequency and severity of typhoons increases. Therefore, climate change could stress populations of taiwania even further and threaten their survival. Conversely, though, wind throw mortality creates gaps that could be beneficial to the maintenance of the species. Regeneration of taiwania requires full sun, and hence, it is difficult to regenerate in natural forests. Seedlings and saplings are mainly found in disturbed and unstable sites with intense light such as forest gaps (He et al. 2015).

Forest managers can do little to ameliorate higher precipitation and typhoons, but management actions can be taken to open up gaps to promote regeneration. Taiwania often grows in mixed species stands ( $\mathrm{He}$ et al. 2015), so species that are not vulnerable (if present) could be removed to create gaps. This would both preserve older taiwania trees by using non-vulnerable species to create gaps and promote the regeneration of taiwania.

Ensuring the continuance of taiwania can be achieved by establishing and managing plantations of this species. Long-term taiwania provenance tests continue to be well-maintained and measured (Chung et al. 2013). These tests are valuable for sustaining the species because the tests contain trees from across the range of populations of taiwania in Taiwan and hence conserve taiwania's genetic diversity.

\section{Conclusions}

Taiwania is an important tree species in Taiwan and is vulnerable to extinction. Mortality of taiwania increases as social status (relative size) decreases and annual precipitation in the year of death increases. The increase in mortality as precipitation increases is likely due to wind throw from typhoons rather than a direct effect of excess moisture, but further work is required to test this hypothesis. Climate change that leads to more precipitation and typhoons may cause mortality that could stress the populations of this already vulnerable species. Therefore, it is increasingly important to consider the role that mortality plays in the stand dynamics of this endangered species.

\section{Additional files}

\section{Additional file 1: Mensuration data for the plots in Compartment 3. (CSV $303 \mathrm{~kb}$ ) \\ Additional file 2: Mensuration data for the plots in Compartment 12. (CSV $547 \mathrm{~kb}$ ) \\ Additional file 3: Climate data. (CSV $2.49 \mathrm{~kb}$ )}

\section{Abbreviations \\ AIC: Akaike information criterion; dbh: Diameter at breast height; sph: Stems per hectare}

\section{Acknowledgements}

We thank Dr. Cheng Ying, retired geneticist from the British Columbia Ministry of Forests and Range, and Peter Ott, British Columbia Ministry of 
Forests, Lands, Natural Resource Operations \& Rural Development, for the review comments on an early version of our manuscript. We are especially grateful for the comments from three anonymous reviewers, which led to a more robust model and a much improved manuscript, both in content and presentation.

\section{Funding}

No funding was required.

\section{Availability of data and materials}

The datasets supporting the conclusions of this article are included in additional files: Additional file 1: Mensuration data for the plots in Compartment 3. Additional file 2: Mensuration data for the plots in Compartment 12. Additional file 3: Climate data.

\section{Authors' contributions}

GN conceived the study, analysed the data, and wrote the manuscript. CMC and CTC provided the mensuration data, contributed ideas, and reviewed the manuscript. $\mathrm{CHC}$ provided the climate data. All authors read and approved the final manuscript.

\section{Ethics approval and consent to participate}

Not applicable

\section{Consent for publication}

Not applicable

\section{Competing interests}

The authors declare that they have no competing interests.

\section{Publisher's Note}

Springer Nature remains neutral with regard to jurisdictional claims in published maps and institutional affiliations.

\section{Author details}

'Taiwan Forestry Research Institute, 53 Nan-Hai Road, Taipei 10066, Taiwan, Republic of China. ${ }^{2}$ Ministry of Forests, Lands and Natural Resource Operations, P.O. Box 9512, Stn. Prov. Govt., Victoria, BC v8W 9C2, Canada.

\section{Received: 6 July 2017 Accepted: 20 March 2018}

\section{Published online: 24 April 2018}

\section{References}

Ainsworth, EA, \& Long, SP. (2005). What have we learned from 15 years of free-air $\mathrm{CO}_{2}$ enrichment (FACE)? A meta-analytic review of the response of photosynthesis, canopy properties and plant production to rising $\mathrm{CO}_{2}$. New Phytologist, 165(2), 351-372.

Allison, PD (2010). Survival analysis using SAS ${ }^{\oplus}$ : A practical guide, (2nd ed.). Cary: SAS Institute Inc

Bigler, C, Gavin, DG, Gunning, C, Veblen, TT. (2007). Drought induces lagged tree mortality in a subalpine forest in the Rocky Mountains. Oikos, 116(12), 1983-1994.

Bugmann, $\mathrm{H}$, \& Bigler, C. (2011). Will the $\mathrm{CO}_{2}$ fertilization effect in forests be offset by reduced tree longevity? Oecologia, 165(2), 533-544.

Burnham, KP, \& Anderson, DR (2002). Model selection and multimodel inference a practical information-theoretic approach, (2nd ed.). New York: Springer.

Camarero, JJ, Gazol, A, Galván, JD, Sangüesa-Barreda, G, Gutiérrez, E. (2015). Disparate effects of global-change drivers on mountain confer forests: Warming-induced growth enhancement in young trees vs. $\mathrm{CO}_{2}$ fertilization in gold trees from wet sites. Global Change Biology, 21(2), 738-749.

Chang, C-T, Lin, C-T, Wang, S-F, Vadeboncoeur, MA. (2011). Assessing growing season beginning and end dates and their relation to climate in Taiwan using satellite data. International Journal of Remote Sensing, 32(18), 5035-5058.

Chen, L, Huang, J-G, Alam, SA, Zhai, L, Dawson, A, Stadt, KJ, Comeau, PG. (2017) Drought causes reduced growth of trembling aspen in western Canada. Global Change Biology, 23(7), 2887-2902.

Chi, C-H, McEwan, RW, Chang, C-T, Zheng, C, Yang, Z, Chiang, J-M, Lin, T-C. (2015). Typhoon disturbance mediates elevational patterns of forest structure, but not species diversity, in humid monsoon Asia. Ecosystems, 18, 1410-1423.
Chung, J-D, Chiu, C-M, Nigh, G, Chien, C-T, Ying, CC. (2013). Genetic variation in wood property and growth of taiwania (Taiwania cryptomerioides Hayata). Silvae Genetica, 62(6), 265-276.

Chung, J-D, \& Kuo, S-R. (2005). Reproductive cycle of Calocedrus formosana. Taiwan Journal of Forest Science, 20, 315-329.

Coomes, DA, \& Allen, RB. (2007). Effects of size, competition and altitude on tree growth. Journal of Ecology, 95, 1084-1097.

Franklin, JF, Shugart, HH, Harmon, ME. (1987). Tree death as an ecological process. Bioscience, 37(8), 550-556.

Grömping, U. (2007). Relative importance for linear regression in R: The package relaimpo. Journal of Statistical Software, 17(1), 1-26. https://doi. org/10.18637/jjj.v017.i01.

He, L-Y, Tang, CQ, Wu, Z-L, Wang, H-C, Ohsawa, M, Yan, K. (2015). Forest structure and regeneration of the tertiary relict Taiwania cryptomerioides in the Gaoligong Mountains, Yunnan, southwestern China. Phytocoenologia, 45(1-2), 135-156.

Hosmer, DW, \& Lemeshow, S (2000). Applied logistic regression. Toronto: John Wiley \& Sons

Hsu, H-H, Chou, C, Wu, Y-C, Lu, M-M, Chen, C-T, Chen, Y-M (2011). Climate change in Taiwan: Scientific report 2011 (summary). Taipei: National Science Council.

Huang, T-C, Shieh, W-C, Keng, H, Tsai, J-L, Hu, J-M, Shen, C-F, Yang, K-C, Yang, S-Y, Hsieh, C-F (1994). Flora of Taiwan. National Science Council of the Republic of China http://tai2.ntu.edu.tw/ebook/ebookcontent.php?book=Fl.

\%20Taiwan\%202nd\%20edit.\&volume=1. Taiwan 2nd edit.\&page=iii. Accessed 3 April 2017

Kozlowski, TT. (1984). Plant responses to flooding of soil. Bioscience, 34(3), 162-167.

Kuo, P-T. (1995). Five major valuable timbers in Taiwan. Taipei: Chinese Forestry Association Bulletin No. 965.

Lee, M-F, Lin, T-C, Vadeboncoeur, MA, Hwong, J-L. (2008). Remote sensing assessment of forest damage in relation to the 1996 strong typhoon herb at Lienhuachi Experimental Forest, Taiwan. Forest Ecology and Management, 255, 3297-3306.

Li, C-F, Chytrý, M, Zelený, D, Chen, M-Y, Chen, T-Y, Chiou, C-R, Hsia, Y-J, Liu, H-Y, Yang, S-Z, Yeh, C-L, Wang, J-C, Yu, C-F, Lai, Y-J, Chao, W-C, Hsieh, C-F. (2013). Classification of Taiwan forest vegetation. Applied Vegetation Science, 16(4), 698-719. https://doi.org/10.1111/avsc.12025.

Lin, K-C, Hamburg, SP, Wang, L, Duh, C-T, Huang, C-M, Chung, C-T, Lin, T-C. (2017). Impacts of increasing typhoons on the structure and function of a subtropical forest: Reflections of a changing climate. Scientific Reports, 7, 4911. https://doi.org/10.1038/s41598-017-05288-y.

Lin, T-C, Hamburg, SP, Llin, K-C, Wang, L-J, Chang, C-T, Hsia, Y-J, Vadeboncoeur, MA, Mabry McMullen, CM, Liu, C-P. (2011). Typhoon disturbance and forest dynamics: Lessons from a northwest Pacific subtropical forest. Ecosystems, 14, 127-143.

Mei, W, Xie, S-P, Primeau, F, McWilliams, JC, Pasquero, C. (2015). Northwestern Pacific typhoon intensity controlled by changes in ocean temperatures. Science Advances, 1(4), 1-8. https://doi.org/10.1126/sciadv.1500014.

Nowak, RS, Ellsworth, DS, Smith, SD. (2004). Functional responses of plants to elevate atmospheric $\mathrm{CO}_{2}$ - do photosynthetic and productivity data from FACE experiments support early predictions? New Phytologist, 162(2), 253-280.

Pedlar, JH, \& McKenney, DW. (2017). Assessing the anticipated growth response of northern conifer populations to a warming climate. Scientific Reports, 7 , 43881. https://doi.org/10.1038/srep43881.

Ryan, MG. (2010). Temperature and tree growth. Tree Physiology, 30(6), 667-668.

SAS Institute Inc (2011). SAS OnlineDoc ${ }^{\circledR}$ 9.3. Cary: SAS Institute Inc.

Shang, H.-G. (2013). Taiwan seeks a balance between forest conservation, forest carbon sinks, and wood production. Silviculture Magazine. http://www. silviculturemagazine.com/articles/spring-2013/taiwan-seeks-balance-betweenforest-conservation-forest-carbon-sinks-and-wood-p. Accessed 9 March 2017

Suresh, HS, Dattaraja, HS, Sukumar, R. (2010). Relationship between annual rainfall and tree mortality in a tropical dry forest: Results of a 19-year study at Mudumalai, southern India. Forest Ecology and Management, 259(4), 762-769.

Taylor, SW, Carroll, AL, Alfaro, RI, Safranyik, L (2006). Forest, climate and mountain pine beetle outbreak dynamics in western Canada. In L Safranyik, B Wilson (Eds.), The mountain pine beetles a synthesis of biology, management, and impacts on lodgepole pine, (pp. 67-94). Victoria: Natural Resources Canada.

Thomas, P, \& Farjon, A (2016). Taiwania cryptomerioides. International Union for Conservation of Nature http://www.iucnredlist.org/details/31255/0. Accessed 8 March 2017.

United Nations Economic Commission for Europe International Co-operative Programme Co-ordinating Centre. (2016). Manual on methods and criteria for 
harmonized sampling, assessment, monitoring and analysis of the effects of air pollution on forests. http://www.icp-forests.org/Manual.htm . Accessed 17 Feb 2017.

van Mantgem, PJ, Stephenson, NL, Byrne, JC, Daniels, LD, Franklin, JF, Fulé, PZ, Harmon, ME, Larson, AJ, Smith, JM, Taylor, AH, Veblen, TT. (2009). Widespread increase of tree mortality rates in the western United States. Science, 323(5913), 521-524.

Wang, BSP, \& Chien, C-T (2016). Seeds of the economically important trees in Taiwan. Taiwan: Taiwan Forestry Research Institute.

Wang, T, O'Neill, GA, Aitken, SN. (2010). Integrating environmental and genetic effects to predict responses of tree populations to climate. Ecological Applications, 20(1), 153-163.

Waring, RH. (1987). Characteristics of trees predisposed to die. Bioscience, 37(8), $569-574$.

Way, DA, \& Oren, R. (2010). Differential responses to changes in growth temperature between trees from different functional groups and biomes: A review and synthesis of data. Tree Physiology, 30(6), 669-688.

Westoby, M. (1984). The self-thinning rule. Advances in Ecological Research, 14, $167-225$.

World Wildlife Fund (2017). Tropical and subtropical moist broadleaf forests southeastern Asia. Taiwan: http://www.worldwildlife.org/ecoregions/im0172. Accessed 8 March 2017

Wu, C-C. (2013). Typhoon Morakot key findings from the journal TAO for improving prediction of extreme rains at landfall. Bulletin of the American Meteorological Society, 94(2), 155-160.

Xu, X, Medvigy, D, Rodriguez-Itrube, I. (2015). Relation between rainfall intensity and savanna tree abundance explained by water use strategies. Proceedings of the National Academy of Sciences, 112(42), 12992-12996.

Yoda, K, Kira, T, Ogawa, H, Hozami, K. (1963). Self thinning in overcrowded pure stands under cultivated and natural conditions: Intraspecific competition among higher plants XI. Journal of Biology Osaka City University, 14, 107-129. Yuan, E (2014). The Republic of China yearbook 2014. Taipei: Executive Yuan.

Zeppel, MJB, Wilks, JV, Lewis, JD. (2014). Impacts of extreme precipitation and seasonal change in precipitation on plants. Biogeosciences, 11(11), 3083-3093.

\section{Submit your manuscript to a SpringerOpen ${ }^{\circ}$ journal and benefit from:}

- Convenient online submission

- Rigorous peer review

- Open access: articles freely available online

- High visibility within the field

- Retaining the copyright to your article

Submit your next manuscript at $\gg$ springeropen.com 